\title{
ЭКСПЕРИМЕНТАЛЬНАЯ МИНЕРАЛОГИЯ
}

DOI https://doi.org/10.30695/zrmo/2019.1485.08

(C) Д. чл. Н. В. ЧУКАНОВ, *,** А. Р. КОТЕЛЬНИКОВ, ***

д. чл. И. В. ПЕКОВ, ** K. В. BAH***

\section{К ВОПРОСУ ОБ УСЛОВИЯХ ОБРАЗОВАНИЯ КАНКРИСИЛИТА $\mathrm{Na}_{7}\left(\mathrm{Al}_{5} \mathrm{Si}_{7} \mathrm{O}_{24}\right)\left(\mathrm{CO}_{3}\right) \cdot 3 \mathrm{H}_{2} \mathrm{O}$ И «ГИДРОКАНКРИНИТА» $\mathrm{Na}_{6}\left(\mathrm{Al}_{6} \mathrm{Si}_{6} \mathrm{O}_{24}\right) \cdot 4 \mathrm{H}_{2} \mathrm{O}$ (НА ОСНОВЕ ДАННЫХ ПО СИНТЕЗУ)}

\author{
* Институт проблем химической физики РАН, \\ 142432, Московская обл., Черноголовка, пр. Семенова, 1; \\ e-mail: chukanov@icp.ac.ru \\ ** Московский государственный университет, геологический факультет, \\ 119991, Москва, Воробьевы горы \\ *** Институт экспериментальной минералогии РАН, \\ 142432, Московская обл., Черноголовка, ул. Академика Осипьяна, 4
}

Синтезированы алюмосиликаты с канкринитовой структурой, по составу отвечающие высококремниевой разновидности канкрисилита и $\mathrm{CO}_{3}$ - дефицитному аналогу канкринита. Эмпирические формулы полученных соединений $-\mathrm{Na}_{6.13}\left[\mathrm{Al}_{4.36} \mathrm{Si}_{7.64} \mathrm{O}_{24}\right]\left(\mathrm{CO}_{3}\right)_{0.91} \cdot 2.85 \mathrm{H}_{2} \mathrm{O}$ и $\mathrm{Na}_{6.19}\left[\mathrm{Al}_{5.53} \mathrm{Si}_{6.47} \mathrm{O}_{24}\right]\left(\mathrm{CO}_{3}\right)_{0.37} \cdot 3.92 \mathrm{H}_{2} \mathrm{O}$ соответственно. Оба образца охарактеризованы методами ИК-спектроскопии и порошковой рентгенографии. Обсуждаются условия образования канкрисилита и карбонат-дефицитного канкринита в природе. Сделан вывод о том, что кристаллизации канкрисилита способствуют надкритические условия и ультраагпаитовая обстановка.

Ключевые слова: минералы группы канкринита, канкринит, канкрисилит, гидротермальный синтез, ИК-спектроскопия, порошковая рентгенография.

\section{N. V. CHUKANOV, ,** A. R. KOTEL'NIKOV, ${ }^{* * *} I . V . P E K O V,{ }^{* *}$ K. V. VAN ${ }^{* * *}$ ON THE CONDITIONS OF THE FORMATION OF CANCRISILITE $\mathrm{Na}_{7}\left(\mathrm{Al}_{5} \mathrm{Si}_{7} \mathrm{O}_{24}\right)\left(\mathrm{CO}_{3}\right) \cdot 3 \mathrm{H}_{2} \mathrm{O}$ AND «HYDROXYCANCRINITE» $\mathrm{Na}_{6}\left(\mathrm{Al}_{6} \mathrm{Si}_{6} \mathrm{O}_{24}\right) \cdot 4 \mathrm{H}_{2} \mathrm{O}$ (ON THE BASIS OF DATA ON SYNTHESIS)

\footnotetext{
* Institute of Problems of Chemical Physics RAS, Chernogolovka, Moscow Region, Russia

** Faculty of Geology, Moscow State University, Moscow, Russia *** Institute of Experimental Mineralogy RAS, Chernogolovka, Moscow Region, Russia
}

Aluminosilicates with a cancrinite-type structure compositionally related to cancrisilite and a Cafree and $\mathrm{CO}_{3}$ - deficient cancrinite analogue were synthesized and characterized by electron microprobe and $\mathrm{HCN}$-analyses, IR spectroscopy, and powder X-ray diffraction. The empirical formulae of the compounds obtained are $\mathrm{H}_{0.05} \mathrm{Na}_{6.13}\left[\mathrm{Al}_{4.36} \mathrm{Si}_{7.64} \mathrm{O}_{24}\right]\left(\mathrm{CO}_{3}\right)_{0.91} \cdot 2.85 \mathrm{H}_{2} \mathrm{O}$ and $\mathrm{H}_{0.07} \mathrm{Na}_{6.19}\left[\mathrm{Al}_{5.53} \mathrm{Si}_{6.47} \mathrm{O}_{24}\right]$. $\cdot\left(\mathrm{CO}_{3}\right)_{0.365} \cdot 3.915 \mathrm{H}_{2} \mathrm{O}$, respectively. The latter compound is characterized by disordered chains $\left(\cdots \mathrm{Na}^{\cdots} \mathrm{H}_{2} \mathrm{O}\right)_{\infty}$ in the narrow channel and a high content of $\mathrm{H}_{2} \mathrm{O}$ in the wide channel. The conditions for the formation of cancrisilite and carbonate-deficient cancrinite varieties in nature are discussed. It was concluded that supercritical conditions and ultra-agpitic environment contribute to crystallization of cancrisilite.

Key words: Cancrinite-group minerals, cancrinite, cancrisilite, hydrothermal synthesis, IR spectroscopy, powder X-ray diffraction. 


\section{ВВЕДЕНИЕ}

Группа канкринита объединяет гексагональные и тригональные фельдшпатоиды с цеолитными каналами и полостями, которые содержат крупные щелочные и щелочноземельные катионы, внекаркасные анионы и молекулы воды. В Al-Si-O-каркасе можно выделить слои из шестичленных колец, образованных алюмосиликатными тетраэдрами. Каждый такой слой сдвинут относительно соседнего на $1 / 3$ периода повторяемости по оси $x$ или $y$. Тип каркаса определяется последовательностью укладки слоев разных типов $(A, B, C)$ вдоль оси $z$ (Bonaccorsi, Merlino, 2005). Наиболее распространенный (и наиболее простой) тип каркаса в канкринитоподобных структурах содержит два тетраэдрических слоя на период повторяемости вдоль оси $z$ (каркас $A B$-типа). Каркас пронизан каналами двух типов (узкими и широкими) в направлении оси $c$. Общая формула таких минералов может быть записана в виде $(\mathrm{Na}, \mathrm{Ca}, \mathrm{K})_{7-8}\left(\mathrm{Si}_{x} \mathrm{Al}_{12-x} \mathrm{O}_{24}\right) A_{y} \cdot n \mathrm{H}_{2} \mathrm{O}$, где $A=\mathrm{CO}_{3}{ }^{2-}, \mathrm{SO}_{4}{ }^{2-}, \mathrm{Cl}^{-}, \mathrm{OH}^{-}, \mathrm{S}^{2-}, \mathrm{PO}_{4}{ }^{3-}, \mathrm{C}_{2} \mathrm{O}_{4}{ }^{2-}$, $x=6-7, y=0.5-4, n=0-5$. В большинстве случаев отношение $\mathrm{Si}: \mathrm{Al}$ близко к $1: 1(x \approx 6)$, но для канкрисилита $\mathrm{Si}: \mathrm{Al} \approx 7: 5$ (при $\mathrm{Na}>>\mathrm{K}, \mathrm{Ca})$, что отражает кристаллизацию этого минерала в ультраагпаитовой обстановке.

Содержание внекаркасных анионов в минералах группы канкринита (МГК) варьирует в широких пределах, достигая наименьших значений в депмайерите $\mathrm{Na}_{8}\left[\mathrm{Al}_{6} \mathrm{Si}_{6} \mathrm{O}_{24}\right]\left(\mathrm{PO}_{4}, \mathrm{CO}_{3}\right)_{0.5-1.0} \cdot 3 \mathrm{H}_{2} \mathrm{O}$ (Пеков и др., 2010), кианоксалите $\mathrm{Na}_{7}\left(\mathrm{Al}_{5-6} \mathrm{Si}_{6-7} \mathrm{O}_{24}\right)\left(\mathrm{C}_{2} \mathrm{O}_{4}\right)_{0.5-1.0} \cdot 5 \mathrm{H}_{2} \mathrm{O}$ (Чуканов и др., 2009), канкрисилите $\mathrm{Na}_{7}\left[\mathrm{Al}_{5} \mathrm{Si}_{7} \mathrm{O}_{24}\right]\left(\mathrm{CO}_{3}\right) \cdot 3 \mathrm{H}_{2} \mathrm{O}$ (Хомяков и др., 1991) и $\mathrm{CO}_{3}$ - дефицитной разновидности канкринита с идеализированной формулой $\mathrm{Na}_{6} \mathrm{Ca}\left(\mathrm{Al}_{6} \mathrm{Si}_{6} \mathrm{O}_{24}\right)$. - $\left(\mathrm{CO}_{3}\right) \cdot 2 \mathrm{H}_{2} \mathrm{O}$ (Олысыч, 2010). Вопрос о существовании в природе МГК, не содержащих внекаркасных анионов, остается открытым. В то же время, среди синтетических соединений такие «канкриниты» известны (Barrer et al., 1970).

В настоящей работе приводятся данные о синтезе, химическом составе, ИК-спектрах и рентгенографических характеристиках аналогов канкрисилита и канкринита с весьма низким содержанием карбонатных групп и в целом внекаркасных анионов.

\section{МЕТОДЫ СИНТЕЗА И ИССЛЕДОВАНИЯ}

Опыты по синтезу проводили в автоклавах объемом 20 мл с термоуплотняемым затвором, конструкции ИЭМ РАН. Исходную навеску загружали в платиновые ампулы диаметром 5 и 7 мм. Точность регулировки и контроля температуры составляла $\pm 3^{\circ} \mathrm{C}$, давления - \pm 50 бар.

Для синтеза аналога $\mathrm{CO}_{3}$ - дефицитного канкринита (обр. № 6287) использовали каолинит из хорошо известного Просяновского месторождения (Украина), реактивы $\mathrm{Na}_{2} \mathrm{CO}_{3}$ (осч), $\mathrm{NaOH}$ (осч) и дистиллированную воду. Вначале смесь 200 мг каолинита и 170 мг карбоната натрия, отвечающую по составу стехиометрии канкринита, загружали в открытую платиновую ампулу диаметром 5 мм и прокаливали при $1000{ }^{\circ} \mathrm{C}$ в течение 6 ч для дегидратации и декарбонатизации. После удаления летучих компонентов температуру повышали до $1200^{\circ} \mathrm{C}$, в результате чего получали расплав. В специальных контрольных опытах было определено время, необходимое для удаления летучих компонентов и образования гомогенного расплава. Отсутствие в стекле (продукте прокаливания) групп $\mathrm{CO}_{3}{ }^{2-}$ подтверждено данными ИК-спектроскопии. Ампулы с наплавленным стеклом заваривали в горячем состоянии (при темпе- 
paтуре $\sim 250-300{ }^{\circ} \mathrm{C}$ ) и помещали в бо́льшие ампулы диаметром 7 мм. В эти ампулы добавляли 300 мкл кипящей дистиллированной воды (количество, необходимое для образования щелочного флюида), малые ампулы прокалывали тонкой иглой под слоем воды и затем заваривали большие ампулы. Ампулы загружали в автоклавы, вводили в режим опыта $\left(t=200{ }^{\circ} \mathrm{C} ; P=0.5\right.$ кбар) и выдерживали в течение 31 сут. Время ввода в режим составляло $2-3$ ч. После выдержки в режиме опыта автоклавы охлаждали в проточной холодной воде за 3-5 мин до комнатной температуры. Контроль герметичности ампул осуществляли весовым методом.

Синтез аналога канкрисилита (обр. № 5832) проводили по аналогичной методике в системе на основе 110 мг смеси альбита, уссингита, геля альбита и аморфного $\mathrm{SiO}_{2}$ (в отношении 1:1:10:3), к которой добавили 60 мкл $\mathrm{H}_{2} \mathrm{O}$ и 214 мкл 10\%-ного $\mathrm{NaOH}$, при $t=400{ }^{\circ} \mathrm{C}, P=1$ кбар. Длительность опыта составляла 35 сут.

Исследование химического состава синтезированных образцов методом рентгеноспектрального микроанализа проводилось с применением растрового электронного микроскопа Tescan Vega-II XMU и системы регистрации рентгеновского излучения и расчета состава образца INCA Energy 450 (режим EDS, ускоряющее напряжение 20 кВ, ток электронного пучка 400 пА). Сканирование производилось по площадкам $20 \times 20$ мкм. Время накопления сигнала составляло $100 \mathrm{c.}$

Определение содержаний $\mathrm{H}_{2} \mathrm{O}$ и $\mathrm{CO}_{2}$ производилось путем газово-хроматографического анализа продуктов прокаливания образцов в атмосфере кислорода при $1200{ }^{\circ} \mathrm{C}$ с использованием HCNS-анализатора Vario Micro cubeanalyser (Elementar GmbH, Германия).

ИК-спектры порошков продуктов синтеза, запрессованных в таблетки c KBr, сняты на спектрофотометре SPECORD 75 IR в диапазоне волновых чисел 400-3800 см-1, при щелевой программе 4. В пучок сравнения помещалась аналогичная таблетка из чистого $\mathrm{KBr}$.

ИК-спектры порошков МГК, запрессованных в таблетки с $\mathrm{KBr}$, сняты на Фурье-спектрометре ALPHA FTIR (Bruker Optics, Германия) в диапазоне волновых чисел 360-3800 $\mathrm{cm}^{-1}$, при разрешающей способности $4 \mathrm{~cm}^{-1}$ и числе сканирований, равном 16. В качестве образца сравнения использовалась аналогичная таблетка из чистого $\mathrm{KBr}$.

Порошковые рентгеновские дифрактограммы продуктов синтеза получены на дифрактометре HZG-4 (Германия) в режиме постоянного сканирования с использованием $\mathrm{Cu} K_{\alpha}$-излучения. В качестве внутреннего стандарта применяли кремний спектральной чистоты.

\section{РЕЗУЛЬТАТЫ ИССЛЕДОВАНИЯ СИНТЕЗИРОВАННЫХ ОБРАЗЦОВ}

По данным сканирующей электронной микроскопии и электронно-зондовых анализов, обр. № 6287 представляет собой компактный агрегат, состоящий из мелких (до 5 мкм) частиц канкринитоподобной фазы и содержащий редкие включения примесных фаз (в основном калиевого полевого шпата и $\mathrm{TiO}_{2}$ ), источником вещества для которых, по-видимому, послужили примеси минералов калия и титана в исходном каолините (рис. 1). Образец № 5832 представляет собой агрегат хорошо образованных гексагональных призматических кристаллов размером до $15 \times 100$ мкм (рис. 2). 


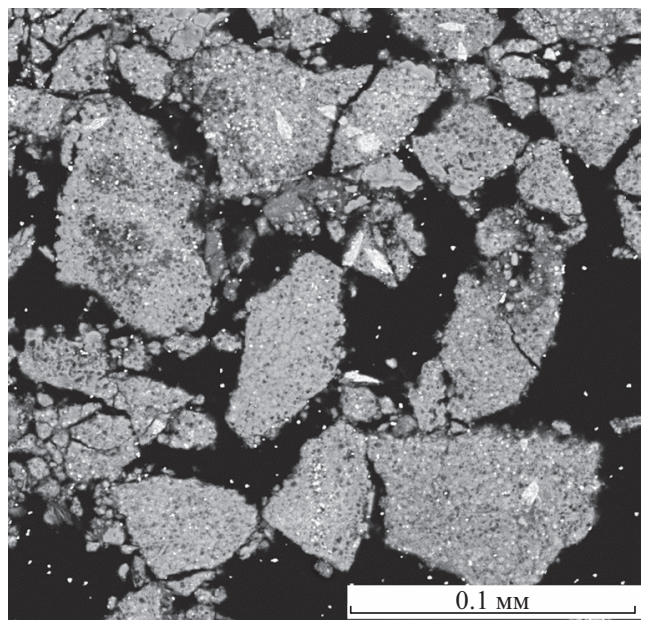

Рис. 2. Образец № 5832. Изображение в отраженных электронах.

Fig. 2. Sample 5832. BSE image.

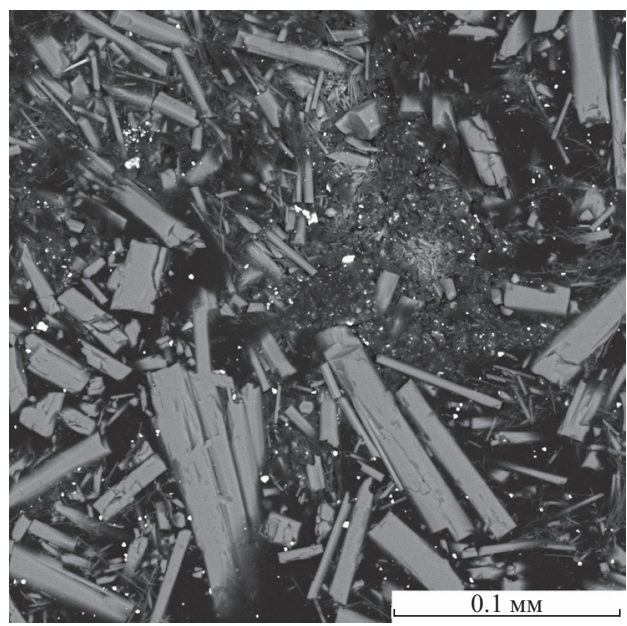

Рис. 1. Образец № 6287. Аншлиф, изображение в отраженных электронах. Светлые зерна - оксид титана.

Fig. 1. Sample 6287. Polished section. BSE image. Light grains are Ti oxide.

Данные о химическом составе продуктов синтеза приведены в табл. 1. Им соответствуют следующие эмпирические формулы:

$$
\begin{aligned}
& \mathrm{CO}_{3} \text {-дефицитный аналог канкринита («гидроканкринит») - } \\
& \qquad \mathrm{Na}_{6.19}\left[\mathrm{Al}_{5.53} \mathrm{Si}_{6.47} \mathrm{O}_{24}\right]\left(\mathrm{CO}_{3}\right)_{0.37} \cdot 3.92 \mathrm{H}_{2} \mathrm{O} ; \\
& \text { аналог канкрисилита }-\mathrm{Na}_{6.13}\left[\mathrm{Al}_{4.36} \mathrm{Si}_{7.64} \mathrm{O}_{24}\right]\left(\mathrm{CO}_{3}\right)_{0.91} \cdot 2.85 \mathrm{H}_{2} \mathrm{O} .
\end{aligned}
$$

Результаты расчета порошковых рентгенограмм обр. № 6287 и 5832 и рассчитанные из этих данных параметры их гексагональных элементарных ячеек приведены в табл. 2. Рентгенограммы однозначно подтверждают принадлежность обоих синтезированных образцов к канкринитам с каркасом типа $A B$. Индицирование рефлексов выполнено с опорой на расчетные порошкограммы канкринита и канкрисилита, для которых определены кристаллические структуры (Олысыч, 2010). Из табл. 2 видно, что все значения межплоскостных

Таблица 1

\begin{tabular}{|c|c|c|c|c|c|c|c|c|}
\hline & \multicolumn{4}{|c|}{$\begin{array}{c}\text { Синтетический «гидроканкринит» } \\
\text { (обр. № 6287) }\end{array}$} & \multicolumn{4}{|c|}{$\begin{array}{c}\text { Синтетический аналог канкрисилита } \\
\text { (обр. № 5832) }\end{array}$} \\
\hline & 1 & 2 & 3 & Средний & 1 & 2 & 3 & Средний \\
\hline $\mathrm{Na}_{2} \mathrm{O}$ & 20.61 & 19.83 & 19.69 & 20.04 & 20.27 & 19.55 & 19.04 & 19.62 \\
\hline $\mathrm{Al}_{2} \mathrm{O}_{3}$ & 29.86 & 29.30 & 29.25 & 29.47 & 23.20 & 22.91 & 22.76 & 22.96 \\
\hline $\mathrm{SiO}_{2}$ & 40.27 & 40.84 & 40.74 & 40.62 & 47.18 & 47.42 & 47.55 & 47.38 \\
\hline $\mathrm{CO}_{2}$ & & & & 1.68 & & & & 4.15 \\
\hline $\mathrm{H}_{2} \mathrm{O}$ & & & & 7.44 & & & & 5.33 \\
\hline Сумма & & & & 99.25 & & & & 99.44 \\
\hline
\end{tabular}

Химический состав продуктов синтеза (мас. \%)

Chemical composition of the products of synthesis (wt \%) 
Результаты расчета порошковых рентгенограмм и параметры элементарных ячеек синтетического «гидроканкринита» (№ 6287) и синтетического аналога канкрисилита (№ 5832)

Powder X-ray diffraction data and unit-cell parameters of synthetic «hydrocancrinite» (№ 6287) and synthetic analogue of cancrisilite (№ 5832)

\begin{tabular}{|c|c|c|c|c|}
\hline \multicolumn{2}{|c|}{ Образец № 6287} & \multicolumn{2}{|c|}{ Образец № 5832} & \multirow{2}{*}{$h k l$} \\
\hline$I, \%$ & $d, \AA$ & $I, \%$ & $d, \AA$ & \\
\hline 64 & 6.38 & 56 & 6.29 & 110 \\
\hline 29 & 5.54 & 14 & 5.45 & 200 \\
\hline 86 & 4.71 & 21 & 4.64 & 101 \\
\hline 52 & 4.18 & 15 & 4.11 & 210 \\
\hline 88 & 3.686 & 100 & 3.629 & 300 \\
\hline 100 & 3.260 & 56 & 3.203 & 211 \\
\hline 3 & 3.067 & 8 & 3.021 & 130 \\
\hline 31 & 3.005 & 5 & 2.959 & 301 \\
\hline 46 & 2.765 & 78 & 2.721 & 400 \\
\hline 13 & 2.643 & 18 & 2.597 & 311 \\
\hline 30 & 2.603 & 11 & 2.548 & 002 \\
\hline 8 & 2.535 & 4 & 2.498 & 320 \\
\hline 45 & 2.447 & 23 & 2.400 & 401 \\
\hline 4 & 2.397 & 4 & 2.375 & 140,112 \\
\hline 11 & 2.281 & 11 & 2.242 & 321 \\
\hline 8 & 2.188 & 4 & 2.176 & 141 \\
\hline 19 & 2.128 & 40 & 2.094 & 330,302 \\
\hline 6 & 2.090 & 3 & 2.056 & 420 \\
\hline 3 & 2.037 & 7 & 2.002 & 501 \\
\hline 3 & 1.987 & 3 & 1.954 & 510 \\
\hline 7 & 1.895 & 7 & 1.856 & 402 \\
\hline 9 & 1.817 & 4 & 1.814 & 340 \\
\hline 4 & 1.807 & 7 & 1.787 & 322 \\
\hline 10 & 1.771 & 15 & 1.742 & 250,412 \\
\hline 4 & 1.717 & 3 & 1.709 & 431 \\
\hline 6 & 1.677 & 8 & 1.670 & 502,521 \\
\hline 4 & 1.647 & & & 203 \\
\hline 12 & 1.597 & 11 & 1.578 & 611,123 \\
\hline 7 & 1.588 & 15 & 1.570 & 440 \\
\hline 7 & 1.568 & 6 & 1.555 & 512 \\
\hline 10 & 1.506 & 14 & 1.487 & 701 \\
\hline 10 & 1.470 & 8 & 1.447 & 261 \\
\hline 8 & 1.465 & 12 & 1.441 & 403 \\
\hline \multicolumn{5}{|c|}{ Параметры гексагональной элементарной ячейки } \\
\hline \multirow{3}{*}{\multicolumn{2}{|c|}{$\begin{array}{c}12.752(2) \\
5.186(1) \\
730.3(4)\end{array}$}} & \multirow{3}{*}{\multicolumn{2}{|c|}{$\begin{array}{c}12.594(2) \\
5.106(1) \\
701.3(4)\end{array}$}} & $a, \AA$ \\
\hline & & & & $c, \AA$ \\
\hline & & & & $V, \AA^{3}$ \\
\hline
\end{tabular}

расстояний и параметры элементарной ячейки у обр. № 5832 (аналог канкрисилита) ощутимо меньше, чем у обр. № 6287 («гидроканкринит»). Это, несомненно, связано с большей величиной $\mathrm{Al}: \mathrm{Si}$-отношения в каркасе последнего.

ИК-спектры синтезированных образцов приведены на рис. 3. Для сравнения на рис. 4 приведены ИК-спектры родственных им МГК. 


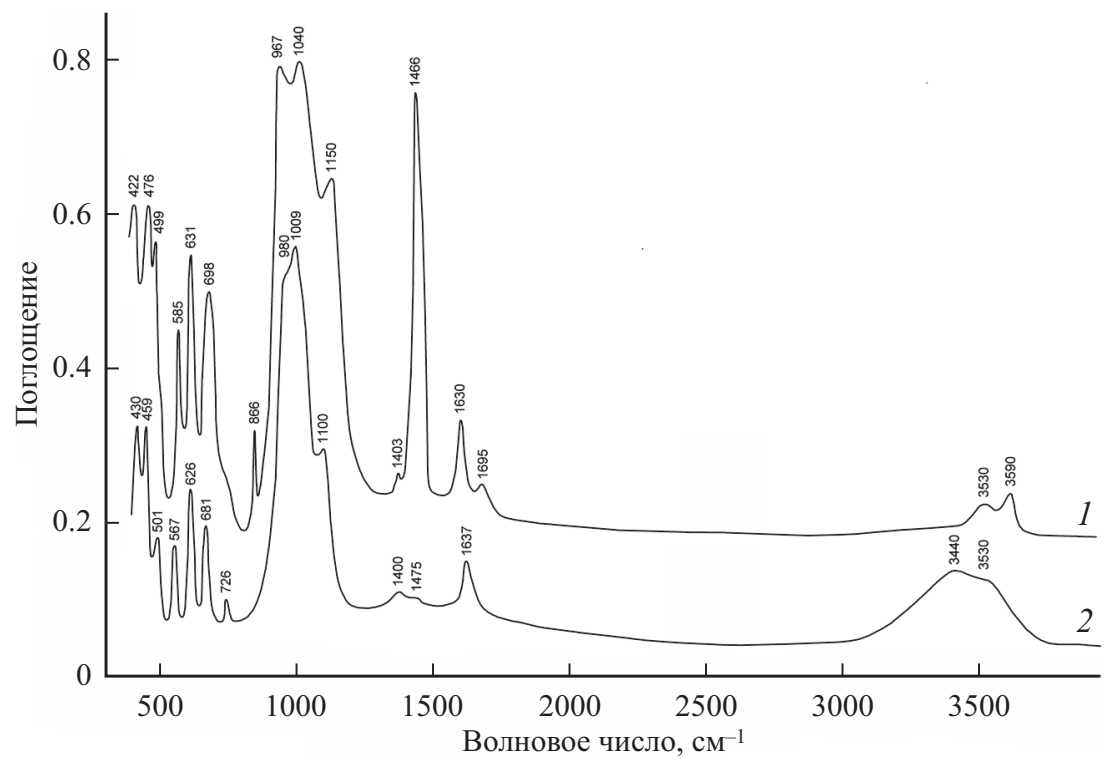

Рис. 3. ИК-спектры обр. № 5832 (1) и 6297 (2).

Fig. 3. IR spectra of the samples 5832 (1) and 6297 (2).

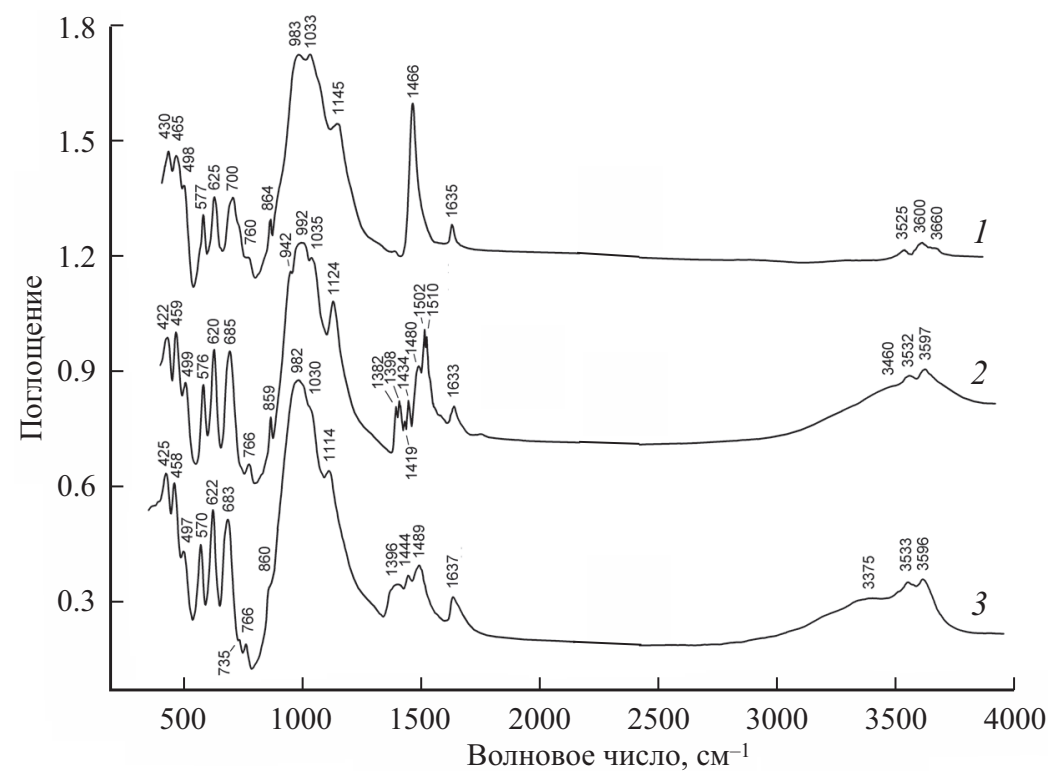

Рис. 4. ИК-спектры высококремниевой разновидности канкрисилита $\mathrm{Na}_{6.93}\left(\mathrm{Al}_{4.34} \mathrm{Si}_{7.66} \mathrm{O}_{24}\right)\left(\mathrm{CO}_{3}\right)_{1.29} \cdot n \mathrm{H}_{2} \mathrm{O}$ из ультраагпаитового пегматита массива Сент-Илер, (Mont Saint-Hilaire), Канада (1), типичного канкринита $\mathrm{Na}_{5.85} \mathrm{Ca}_{1.4} \mathrm{~K}_{0.05}\left(\mathrm{Si}_{6.1} \mathrm{Al}_{5.9} \mathrm{O}_{24}\right)\left(\mathrm{CO}_{3}\right)_{1.4} \cdot n \mathrm{H}_{2} \mathrm{O}$ из щелочного пегматита Ковдорского массива, Кольский полуостров (2), и минерала ряда канкринит-«гидроканкринит» состава $\mathrm{Na}_{7.65} \mathrm{~K}_{0.05} \mathrm{Ca}_{0.04}\left(\mathrm{Al}_{5.71} \mathrm{Si}_{6.28} \mathrm{Fe}_{0.01} \mathrm{O}_{24}\right)\left(\mathrm{CO}_{3}\right)_{0.95}\left(\mathrm{SO}_{4}\right)_{0.07} \mathrm{Cl}_{0.02} \cdot 2.6 \mathrm{H}_{2} \mathrm{O}$ (пр. гр. P3) из щелочного пегматита Ковдорского массива (3) (по данным из справочника Chukanov, 2014).

Fig. 4. IR spectra of a high-silicon cancrisilite variety $\mathrm{Na}_{6.93}\left(\mathrm{Al}_{4.34} \mathrm{Si}_{7.66} \mathrm{O}_{24}\right)\left(\mathrm{CO}_{3}\right)_{1.29} \cdot n \mathrm{H}_{2} \mathrm{O}$ from the Mont Saint-Hilaire ultra-agpaite massif, Canada (1), a typical cancrinite $\mathrm{Na}_{5.85} \mathrm{Ca}_{1.4} \mathrm{~K}_{0.05}\left(\mathrm{Si}_{6.1} \mathrm{Al}_{5.9} \mathrm{O}_{24}\right)\left(\mathrm{CO}_{3}\right)_{1.4} \cdot n \mathrm{H}_{2} \mathrm{O}$ from an alkaline pegmatite of the Kovdor massif, Kola Peninsula (2) and a member of the cancrinite-,,hydrocancrinite" series $\mathrm{Na}_{7.65} \mathrm{~K}_{0.05} \mathrm{Ca}_{0.04}\left(\mathrm{Al}_{5.71} \mathrm{Si}_{6.28} \mathrm{Fe}_{0.01} \mathrm{O}_{24}\right)\left(\mathrm{CO}_{3}\right)_{0.95}\left(\mathrm{SO}_{4}\right)_{0.07} \mathrm{Cl}_{0.02} \cdot 2.6 \mathrm{H}_{2} \mathrm{O}$ (space group P3) from an alkaline pegmatite of the Kovdor massif (3) (the spectra are drawn using data from Chukanov, 2014). 


\section{ОБСУЖДЕНИЕ РЕЗУЛЬТАТОВ}

Как можно видеть из приведенных выше данных, синтетические «гидроканкринит» (обр. № 6287) и аналог канкрисилита (обр. № 5832) по химическому составу, параметрам элементарных ячеек и ИК-спектрам близки к природным образцам $\mathrm{CO}_{3}$-дефицитного аналога канкринита и канкрисилита соответственно. В то же время, синтетические образцы имеют ряд индивидуальных особенностей. Уточненная на основании изучения химического состава и кристаллических структур большой выборки образцов идеализированная формула канкринита - $\mathrm{Na}_{7} \mathrm{Ca}\left[\mathrm{Al}_{6} \mathrm{Si}_{6} \mathrm{O}_{24}\right]\left(\mathrm{CO}_{3}\right)_{1.5} \cdot 2 \mathrm{H}_{2} \mathrm{O}$ (Pekov et al., 2011), a пределы содержаний различных компонентов в этом минерале могут быть выражены упрощенной формулой $\mathrm{Na}_{6-8} \mathrm{Ca}_{0-2}\left[\mathrm{Al}_{5.5-6} \mathrm{Si}_{6-6.5} \mathrm{O}_{24}\right]\left(\mathrm{CO}_{3}\right)_{1-2} \cdot 2-3 \mathrm{H}_{2} \mathrm{O}$ (здесь не учитываются содержания примесных компонентов $\mathrm{K}, \mathrm{Fe}^{3+}, \mathrm{SO}_{4}{ }^{2-}, \mathrm{Cl}^{-}$, $\mathrm{C}_{2} \mathrm{O}_{4}{ }^{2-}$ и др.).

Аналоги канкринита с содержанием карбонатных групп менее 1.0 на формулу крайне редки в природе, а МГК, в которых содержание внекаркасных анионов менее 0.5, и вовсе неизвестны. Успешный синтез «гидроканкринита» показывает возможность существования $\mathrm{CO}_{3}$-дефицитного аналога канкринита как минимум с $\left(\mathrm{CO}_{3}\right)_{0.365}$, однако не исключено, что и в этом случае карбонатные группы играют роль компонента, стабилизирующего структуру канкринитового типа. Тот факт, что «гидроканкринит» не образует совершенных кристаллов, позволяет предположить, что фаза такого состава находится вблизи границы области своей термодинамической стабильности.

Из-за отсутствия монокристаллов обр. № 6287 предположения о его кристаллохимических особенностях можно сделать лишь на основе химического состава и данных ИК-спектроскопии. В ИК-спектре собственно канкринита дублет в области 3500-3600 см-1 относится в валентным колебаниям воды в цепочках $\left(\cdots \mathrm{Na} \cdots \mathrm{H}_{2} \mathrm{O}\right)_{\infty}$ в узком канале. В ИК-спектре обр. № 6297 в этой области наблюдается лишь плечо, что говорит о неупорядоченности строения этих цепочек. Широкая полоса с максимумом в диапазоне $3320-3450 \mathrm{~cm}^{-1}$ в ИК-спектрах канкринита относится к молекулам воды в широком канале (Chukanov et al., 2011). Таким образом, широкая полоса при $3440 \mathrm{~cm}^{-1}$ в ИК-спектре обр. № 6297 относится к молекулам воды, замещающим часть натрия в широком канале «гидроканкринита».

В ИК-спектрах МГК с каркасом $A B$-типа присутствует триплет в области 550 - $704 \mathrm{~cm}^{-1}$ (полосы $v_{\text {I }}, v_{\text {II }}$ и $v_{\text {III }}$ в интервалах 550-585, 608-630 и 667$704 \mathrm{~cm}^{-1}$ соответственно). Ранее нами было показано (Chukanov et al., 2011), что положения полос $v_{\text {I }}$ и $v_{\text {III }}$ зависят от состава внекаркасных анионов, а также от отношения Si:Al. На рис. 5 показана зависимость $v_{\mathrm{I}}\left(v_{\text {III }}\right)$ для различных МГК с каркасом $A B$-типа. Как видно из этой диаграммы, канкринит характеризуется в среднем существенно более высокой частотой полосы $v_{\mathrm{I}}$, чем его низководные аналоги (включая обр. № 6287). Для канкринита с идеализированной формулой $\mathrm{Na}_{6} \mathrm{Ca}\left(\mathrm{Al}_{6} \mathrm{Si}_{6} \mathrm{O}_{24}\right)\left(\mathrm{CO}_{3}\right) \cdot 2 \mathrm{H}_{2} \mathrm{O} v_{\mathrm{I}}=577 \mathrm{~cm}^{-1}$, а $v_{\text {III }}=685 \mathrm{~cm}^{-1}$. Уменьшение содержания групп $\mathrm{CO}_{3}{ }^{2-}$ и рост содержания воды сопровождаются сдвигом полосы $v_{\text {I }}$ в низкочастотную область спектра. Возрастание отношения Si:Al от 6:6 до 7:5 сопровождается увеличением частоты $v_{\text {III }}$.

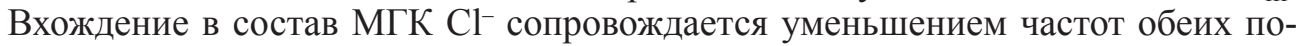

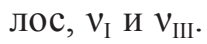

Точки для канкрисилита и его синтетического аналога занимают на диаграмме $v_{\text {I }}\left(v_{\text {III }}\right)$ область с наиболее высокими значениями $v_{\text {III }}$, причем обр. № 5832 


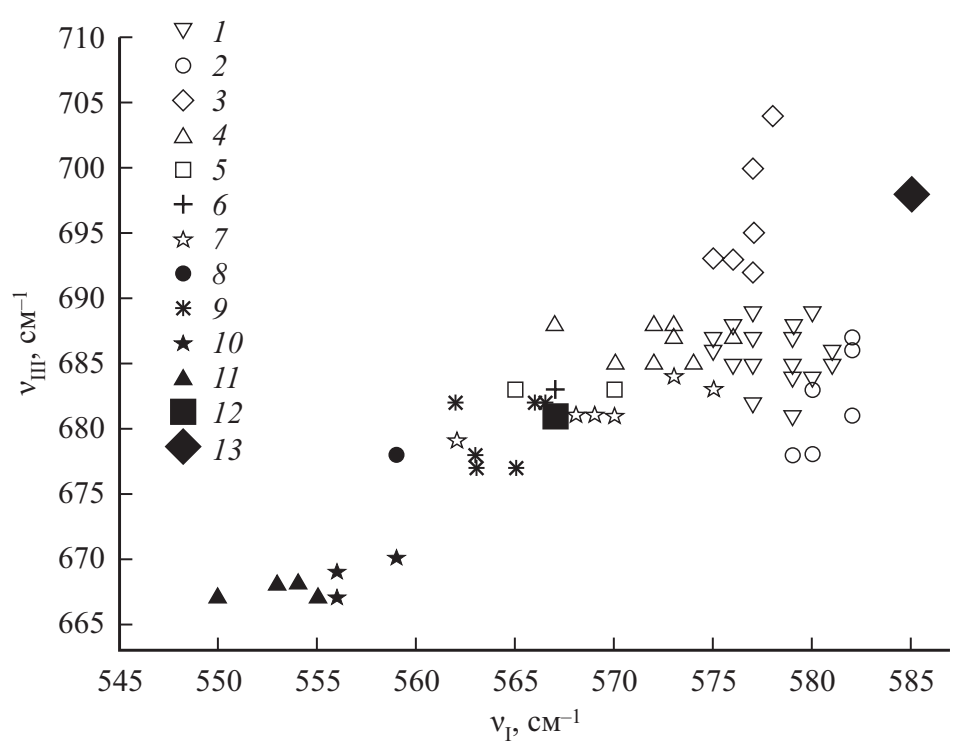

Рис. 5. Положения полос $v_{\mathrm{I}}$ и $v_{\text {III }}$ в ИК-спектрах канкринита (1), низководного аналога канкринита (2), канкрисилита (3), кианоксалита и минералов ряда канкринит-кианоксалит (4), $\mathrm{CO}_{3}$-дефицитного аналога канкринита (5), депмайерита (6), вишневита (7), питильяноита (8), баллираноита и членов ряда давин-баллираноит (9), давина (10), квадридавина (11), а также изученных в настоящей работе синтетического «гидроканкринита», обр. № 6287 (12), и синтетического аналога канкрисилита, обр. № 5832 (13).

Fig. 5. Wavenumbers of absorption maxima of the bands $v_{\mathrm{I}}$ and $v_{\mathrm{III}}$ in IR spectra of cancrinite $(1)$, $\mathrm{H}_{2} \mathrm{O}$-poor cancrinite (2), cancrisilite (3), kyanoxalite and $\mathrm{C}_{2} \mathrm{O}_{4}$-rich members of the cancrinite-kyanoxalite series (4), $\mathrm{CO}_{3}$-deficient cancrinite analogue (5), depmeierite (6), vishnevite (7), pitiglianoite (8), balliranoite and $\mathrm{CO}_{3}$-rich members of the davyne-balliranoite series (9), davyne (10), quadridavyne (11), as well as the samples 6287 (12) and 5832 (13).

имеет и наиболее высокое значение параметра $v_{\text {I }}$, что отражает особенность его химического состава (отношение Si:Al более высокое, чем во всех известных природных образцах канкрисилита). Отсюда можно сделать вывод, что возрастание отношения Si:Al от 7:5 до 8:4 сопровождается увеличением частоты $v_{\mathrm{III}}$. Следует отметить, что в ИК-спектре канкрисилита, приведенном при первом описании этого минерала (Хомяков и др., 1991), частоты сильно занижены (систематическая погрешность для всех полос составляет около $-15 \mathrm{~cm}^{-1}$ ).

Высокое содержание кремния проявляется и в величине расщепления полосы валентных колебаний каркаса в области 950-1050 $\mathrm{cm}^{-1}$. В природных образцах расщепление проявляется тем сильнее, чем выше отношение Si:Al (Chukanov, 2014), а для обр. № 5832 величина этого расщепления наибольшая и составляет $73 \mathrm{~cm}^{-1}$.

Еще одной особенностью канкрисилита, отличающей его от всех других $\mathrm{CO}_{3}$-содержащих МГК, является присутствие в области валентных колебаний карбонатных групп интенсивного синглета при $1466 \mathrm{~cm}^{-1}$ (иногда в этой области присутствует и очень слабая дополнительная полоса при $1400-1405 \mathrm{~cm}^{-1}$ ). Отсутствие расщепления полосы асимметричных C-O-валентных колебаний связано с разобщенностью карбонатных групп в канале и, следовательно, отсутствием резонанса их колебаний. Несмотря на особенности химического состава синтетического аналога канкрисилита, полнопрофильный ИКС-анализ (Чуканов и др., 2008) показал вклад канкрисилита в ИК-спектр обр. № 5832, 
равный 72 \%, тогда как вклад любого другого МГК составляет менее 7 \% (Dubovitskiy, Chukanov, 2009).

Из условий синтеза обр. № 5832 можно сделать вывод о том, что для кристаллизации канкрисилита требуются более высокая температура и более высокоагпаитовая обстановка, чем для образования «гидроканкринита». Если в части агпаитности это очевидно (см. Введение), то в части температуры представляется более интересным. Канкрисилит встречается в ультращелочных дифференциатах нескольких массивов агпаитовых нефелиновых сиенитов (Олысыч, 2010; Pekov et al., 2011), и диапазон обстановок его нахождения весьма широк: от собственно пегматитовых минеральных ассоциаций до позднегидротермальных, с широкопористыми цеолитами. Условия, при которых синтезирован аналог этого минерала, говорят о том, что кристаллизация канкрисилита при температурах выше критической точки воды, т. е. на определенно «догидротермальных» стадиях эволюции ультраагпаитовых систем, вполне возможна.

В то же время, можно надеяться, что в природе будет обнаружен и «гидроканкринит» - водный МГК, сильно обедненный внекаркасными анионами. Данные по условиям синтеза обр. № 6287 позволяют предположить, что он, вероятнее всего, может быть встречен в цеолитовых гидротермалитах, связанных с агпаитовыми породами.

\section{ВЫВОДЫ}

Полученные результаты свидетельствуют, что возможно существование алюмосиликатов со структурой канкринита, в которых общий заряд внекаркасных анионов существенно ниже 1 при общем содержании воды около 4 молекул на формулы («гидроканкринит»). Основываясь на данных по синтезу, можно ожидать присутствие подобных минералов в природных низкотемпературных гидротермальных ассоциациях.

Содержание кремния в канкрисилите может существенно превышать идеальное значение (7 атомов на формулу). Образованию высококремниевой разновидности канкрисилита способствуют надкритические условия и ультраагпаитовая обстановка.

Работа выполнена при финансовой поддержке Российского фонда фундаментальных исследований, грант 18-29-12007_мк. ИК-спектроскопические исследования выполнены по теме государственного задания, № государственной регистрации 0089-2019-0013.

\section{Список литературы}

Олысыч Л. В. Структурная и генетическая минералогия группы канкринита в интрузивных щелочных комплексах. Дис. ... канд. геол.-минерал. наук М, МГУ, 2010. 307 с.

Пеков И. В., Ольсыч Л. В., Зубкова Н. В., Чуканов Н. В., Ван К. В., Пущаровский Д. Ю. Депмайерит $\mathrm{Na}_{8}\left[\mathrm{Al}_{6} \mathrm{Si}_{6} \mathrm{O}_{24}\right]\left(\mathrm{PO}_{4}, \mathrm{CO}_{3}\right)_{1-x} \cdot 3 \mathrm{H}_{2} \mathrm{O}(x<0.5)$ - новый минерал группы канкринита из Ловозерского щелочного массива (Кольский полуостров, Россия) // ЗРМО. 2010. № 4. С. 63-74.

Хомяков А. П., Семенов Е. И., Победимская Е. А., Надежина Т. Н., Расиветаева Р. К. Канкрисилит $\mathrm{Na}_{7}\left[\mathrm{Al}_{5} \mathrm{Si}_{7} \mathrm{O}_{24}\right] \mathrm{CO}_{3} \cdot 3 \mathrm{H}_{2} \mathrm{O}$ - новый минерал семейства канкринита // 3ВМО. 1991. № 6. C. $80-84$.

Чуканов Н. В., Пеков И. В., Ольссыч Л. В., Масса В., Якубович О. В., Задов А. Е., Расиветаева Р. К., Вигасина М. Ф. Кианоксалит - новый минерал группы канкринита с оксалатным вне- 
каркасным анионом из Ловозерского щелочного массива (Кольский полуостров) // ЗРМО. 2009. № 6. C. $18-35$.

Чуканов Н. В., Дубовиикий В. А., Возчикова С. А., Орлова С. М. Дискретный и функционально-геометрический методы ИКС-анализа минералов с использованием эталонов // ЗРМО. 2008. № 1. С. $77-93$.

\section{References}

Barrer R. M., Cole J. F., Villiger H. Chemistry of soil minerals. Part VII. Synthesis, properties, and crystal structures of salt-filled cancrinites. J. Chem. Soc. A: Inorganic, Physical, Theoretical. 1970. Iss. 0. P. $1523-1531$.

Bonaccorsi E., Merlino S. Modular microporous minerals: Cancrinite-Davyne group and C-S-H phases. Revs. Mineral. Geochem. 2005. Vol. 57. P. 241-290.

Chukanov N. V., Dubovitsky V. A., Vozchikova S. A., Orlova S. M. Discrete and functional-geometric methods of infrared spectroscopy of minerals using reference samples. Zapiski RMO (Proc. Russian Miner. Soc.). 2008. No. 1. P. 77 -93 (in Russian, English translation: Geol. Ore Deposits. 2008. Vol. 50. No. 8. P. 815-826).

Chukanov N. V., Pekov I. V., Olysych L. V., Massa W., Zadov A. E., Rastsvetaeva R. K., Vigasina M. F. Kyanoxalite, a new cancrinite-group mineral species with extraframework oxalate anion from the Lovozero alkaline pluton, Kola peninsula. Zapiski RMO (Proc. Russian Miner. Soc.). 2009. No. 6. P. 18-35 (in Russian, English translation: Geol. Ore Deposits. 2010. Vol. 52. No. 8. P. 778-790).

Chukanov N. V., Pekov I. V., Olysych L. V., Zubkova N. V., Vigasina M. F. Crystal chemistry of cancrinite-group minerals with $A B$-type frameworks. II. IR spectroscopy and its crystal chemical implications: review and new data. Canad. Miner. 2011. Vol. 49. No. 5. P. 1151-1164.

Chukanov N. V. Infrared spectra of mineral species: Extended library. Dordrecht; Heidelberg; New York; London: Springer-Verlag GmbH, 2014. 1716 p.

Dubovitskiy V. A., Chukanov N. V. A functional-geometric method of the analysis of minerals by means of IR spectroscopy. In: Abs. Int. Symp. «Minerale der Sodalith- und Cancrinit-Gruppen sowie verwandte synthetische Verbindungen: Strukturelle Komplexitaet und Variabilitaet, sowie ihre Beziehung zum Eifelvulkanismus». Kiel: Kiel University, 2009. P. 5-6.

Khomyakov A. P., Semenov E. I., Pobedimskaya E. A., Nadezhina T. N., Rastsvetaeva R. K. Cancrisilite $\mathrm{Na}_{7}\left[\mathrm{Al}_{5} \mathrm{Si}_{7} \mathrm{O}_{24}\right] \mathrm{CO}_{3} \cdot 3 \mathrm{H}_{2} \mathrm{O}$, a new cancrinite-group mineral. Zapiski RMO. (Proc. Russian Miner. Soc.). 1991. No. 6. P. $80-84$ (in Russian).

Olysych L. V. Structural and genetic mineralogy of the cancrinite group in intrusive alkaline complexes. Ph. D. thesis. Moscow: Moscow State University, 2010. 307 p. (in Russian).

Pekov I. V., Olysych L. V., Zubkova N. V., Chukanov N. V., Van K. V., Pushcharovsky D. I. Depmeierite $\mathrm{Na}_{8}\left[\mathrm{Al}_{6} \mathrm{Si}_{6} \mathrm{O}_{24}\right]\left(\mathrm{PO}_{4}, \mathrm{CO}_{3}\right)_{1-x} \cdot 3 \mathrm{H}_{2} \mathrm{O}(x<0.5)$ : A new cancrinite-group mineral species from the Lovozero alkaline pluton of the Kola Peninsula. Zapiski RMO (Proc. Russian Miner. Soc.). 2010. No. 4. P. $63-74$ (in Russian, English translation: Geol. Ore Deposits. 2011. Vol. 53. No. 7. P. 604-613).

Pekov I. V., Olysych L. V., Chukanov N. V., Zubkova N. V., Pushcharovsky D. Yu., Van K. V., Giester G., Tillmanns E. Crystal chemistry of cancrinite-group minerals with $A B$-type frameworks. I. Chemical and structural variations: review and new data. Canad. Miner. 2011. Vol. 49. No. 5. P. $1129-1150$. 